\title{
Carbon Monoxide and Soot Emissions from Buoyant Turbulent Diffusion Flames
}

\author{
U. Ö. KÖYLU, Y. R. SIVATHANU and G. M. FAETH \\ Department of Aerospace Engineering \\ The University of Michigan \\ Ann Arbor, Michigan 48109-2140, USA
}

\begin{abstract}
Carbon monoxide concentrations and mixture fractions were measured in the fuel-lean (overfire) region of turbulent acetylene, propylene, ethylene, propane and methane diffusion flames burning in still air. Three burners (having exit diameters of 5, 50 and $234 \mathrm{~mm}$ ) were used to study conditions ranging from buoyant jet flames to pool-like fires. Carbon monoxide generation factors (mass of $\mathrm{CO}$ emitted per unit mass of fuel carbon burned) were uniform throughout the overfire region for a given flame condition. Additionally, $\mathrm{CO}$ generation factors of sooting fuels approached asymptotic values for flame residence times roughly an order of magnitude longer than the normal smoke point residence time, similar to earlier measurements of soot generation factors for similar conditions. Finally, processes of carbon monoxide and soot emission appear to be closely related due to the good correlation between their emission factors in the asymptotic regime: 0.34 (standard deviation of 0.09 ) $\mathrm{kg} \mathrm{CO} / \mathrm{kg}$ soot. However, nonsooting methane/air flames still emitted low levels of $\mathrm{CO}$ so that there is a component of CO emissions that is not associated with soot. KEYWORDS: Fire Physics, Toxic Hazard
\end{abstract}

\section{INTRODUCTION}

The objective of the present investigation was to study the emission of carbon monoxide from buoyant turbulent diffusion flames representative of overventilated natural fires, and to examine whether there is a relationship between carbon monoxide and soot emissions from these flames. There are two main motivations for the work. First of all, carbon monoxide and soot represent major hazards of fire environments: inhalation of carbon monoxide is a major cause of fatalities in fires, while the presence of soot obscures fire fighting efforts and increases flame spread and burning rates due to increased radiation from soot. Secondly, past studies suggest a correspondence between carbon monoxide and soot emissions [1-5], that has important implications concerning materials properties for improved fire safety and a better fundamental understanding of the phenomena causing these emissions. Thus, the present study of $\mathrm{CO}$ emissions was combined with a companion study of soot emissions for similar test conditions [6] to examine this correspondence.

Gas species and soot concentrations within flames provide the setting for their emissions. For buoyant turbulent diffusion flames, that generally have modest stretch rates, this information is most concisely represented by the laminar flamelet concept due to Bilger [7]. He found that existing measurements of the concentrations of major gas species within laminar propane and $\mathrm{n}$-heptane flames could be correlated solely as a function of mixture fraction (or fuel-equivalence ratio) for a particular fuel/air combination over a wide range of burning rates. He also proposed using these correlations (called state relationships) to 
estimate compositions from mixing levels in turbulent flames - treating them like wrinkled laminar flames. Subsequent evaluation of the laminar flamelet concept for buoyant turbulent diffusion flames was reasonably successful, see [8] and references cited therein, while recent work has found generalized state relationships for hydrocarbon-air flames based on laminar flame measurements for a wide variety of fuels [9]. These generalized state relationships show that species concentrations approximate thermodynamic equilibrium for fuel-lean conditions but that processes of fuel decomposition and soot chemistry yield relatively universal departures from equilibrium for near-stoichiometric and fuel-rich conditions. This involves levels of $\mathrm{CO}$ significantly higher than equilibrium for fuel-rich conditions, which is probably the main reason for large $\mathrm{CO}$ emissions from underventilated fires [2]. However, these correlations yield negligibly small concentrations of $\mathrm{CO}$ at low fuel-equivalence ratios, agreeing with equilibrium predictions [9] as well as computations based on relatively complete chemical mechanisms [10]. Additionally, state relationships for carbon monoxide/air flames themselves exhibit negligible concentrations of $\mathrm{CO}$ for fuel-lean conditions [11].

Notwithstanding the state relationships, it is well known that $\mathrm{CO}$ is emitted from turbulent hydrocarbon/air diffusion flames [1-5]. One reason for this discrepancy is that state relationships usually are measured using gas chromatography having limited sensitivity so that the small $\mathrm{CO}$ concentrations of emissions are not resolved. However, recognizing the association between $\mathrm{CO}$ and soot emissions [1] provides an explanation accounting for predictions of low $\mathrm{CO}$ emissions $[9,10]$ as well. In particular, state relationships are usually measured normal to laminar flame surfaces, rather than through the flame tip, to reduce problems of sampling probe clogging with soot [7-9]. Similarly, computations of flame structure ignore the presence of soot due to limited understanding of soot chemistry [10]. Thus, the $\mathrm{CO}$ emitted from hydrocarbon diffusion flames may simply be accompanying the soot being emitted from the tips of laminar flames and turbulent flamelets. This is supported by measurements of soot volume fraction state relationships in laminar flames which show the presence of a soot layer (or soot spike) just on the fuel rich side of stoichiometric - a region also involving maximum $\mathrm{CO}$ concentrations [8,9]. Then, since $\mathrm{CO}$ and soot oxidation are somewhat similar, e.g., soot generally oxidizes to $\mathrm{CO}$ as a first step and $\mathrm{OH}$ plays a strong role in oxidizing both $\mathrm{CO}$ and soot, incomplete oxidation of soot implies analogous behavior for $\mathrm{CO}$. Quenching due to heat losses by continuum radiation from soot may also be a factor. Correlations between instantaneous temperatures and soot concentrations in turbulent flames exhibit lower temperatures in the soot layer for fuels having higher soot concentrations [12]. Then reduced rates of oxidation of $\mathrm{CO}$ at lower temperatures would help explain the trend of increased $\mathrm{CO}$ emissions with increased soot emissions for turbulent diffusion flames [1-5].

Earlier work in this laboratory examined soot emissions from turbulent diffusion flames [6]. It was found that the soot generation factor, $\eta_{\mathrm{s}}$, defined as the mass of soot emitted per unit mass of fuel carbon burned (note that this definition differs from soot yield, which is the mass of soot per unit mass of fuel burned, that has been used by others $[2,3]$ ), was relatively independent of position in the overfire (fuel-lean) region. This indicates both passive mixing of soot in the overfire region, and uniform conditions in the soot layer when chemical reactions are quenched at all points along the flame surface. Additionally, $\eta_{\mathrm{s}}$ increased with increasing flame residence time but eventually reached asymptotic values for residence times roughly an order of magnitude longer than the normal smoke point residence time. Thus, the objective of the present study was to see whether the carbon monoxide generation factor, $\eta_{\mathrm{CO}}$, defined as the mass of $\mathrm{CO}$ emitted per unit mass of fuel carbon burned, behaved in the same manner as $\eta_{\mathrm{s}}$, and whether there was a correspondence between $\eta_{\mathrm{CO}}$ and $\eta_{\mathrm{s}}$. The experiments involved the same test conditions as [6] for acetylene, propylene, ethylene and propane flames burning in air so that information on $\eta_{s}$, was known. The present study also considered methane/air flames, as a limit, because they emitted no soot for present test conditions. 


\section{EXPERIMENTAL METHODS}

Apparatus. The test apparatus is described in [6]. The experiments involved vertically upward injection of fuel in still air within a large enclosure $(2.4 \times 2.4 \times 3.6 \mathrm{~m}$ high $)$ with the exhaust products removed through a hood at the top. Three water-cooled burners, having exit diameters, $d$, of 5,50 and $234 \mathrm{~mm}$, were used to provide a variety of flame conditions. The flames attached naturally on the 50 and $234 \mathrm{~mm}$ diameter burners but a small coflow of hydrogen was needed to attach the flames on the $5 \mathrm{~mm}$ diameter burner.

Instrumentation. Earlier measurements [6], included: flame heights and residence times, mean soot volume fractions, mean mixture fractions, and radiative heat loss fractions: During the present investigation, both $\mathrm{CO}$ concentrations and mixture fractions were measured with a sampling probe. Only the $\mathrm{CO}$ measurements will be discussed in the following because other measurements were identical to [6].

Measurements were made in the far-overfire region (mean fuel-equivalence ratios less than 0.1 and mean temperatures less than $500 \mathrm{~K}$ ), where relationships between mean and instantaneous scalar properties in turbulent flames are the same [6]. Carbon monoxide concentrations were measured using an NDIR instrument (Beckman, Model 867). The sample was dried and filtered before entering the analyzer to minimize uncertainties from the presence of water vapor and particulates. Experimental uncertainties (95\% confidence) of the $\mathrm{CO}$ measurements were dominated by limited sensitivity due to overlap of the infrared gas bands of $\mathrm{CO}$ and $\mathrm{CO}_{2}$ and finite sampling times. They are estimated to be less than $10 \%$ for concentrations greater than $10 \mathrm{ppm}$, increasing inversely with concentration for lower values. Uncertainties of the mixture fraction measurements were the same as [6]: less than $10 \%$ for the concentration of major gas species and less than $20 \%$ for mixture fractions.

Test Conditions. Test conditions are summarized in Table 1. Reynolds numbers, Re, are based on burner exit conditions and will be used to identify particular flames. Flames for the $5 \mathrm{~mm}$ diameter burner were buoyant jet flames; the remainder were highly buoyant and approximated pool-like fires. All the flames were turbulent, except near their base, in spite of

the low initial Reynolds numbers of the pool-like fires. Heat release rates, Qf, were in the range $2.3-33.5 \mathrm{~kW}$ with flame heights, $\mathrm{L}$, of $165-1050 \mathrm{~mm}$. Residence times, $\mathrm{t}_{\mathrm{r}}$, were measured as the time between ending the bumer flow (with a shutter) and the disappearance of all flame luminosity: additional discussion of these measurements as well as correlations of flame lengths and residence times for the pool-like fires can be found in [6]. (Note that there is an error in the $t_{r}$ correlation of [6]: both the ordinate of Fig. 4 and the coefficient of Eq. (4) should be divided by 1000 ). Radiative heat loss fractions, $\mathrm{q}_{\mathrm{r}}$, normal smoke point flame lengths, $L_{S}$, and normal smoke point residence times, $t_{S}$, are also given in Table 1 for each fuel, except for methane where $L_{S}$ and $t_{s}$ are unknown because these flames become turbulent without emitting soot using existing methods to determine these properties. Typical of buoyant flames [13], the radiative heat loss fractions of the flames varied with the fuel but not the flame operating condition. Present values of $L_{S}$ are similar to Schug et al. [14] with slight differences attributed to somewhat different flame operating conditions [6]. Carbon monoxide concentrations were measured in the far-overfire region: at the axis and $r / x=0.08$, where $r$ is radial distance and $\mathrm{x}$ is height above the burner exit; with $\mathrm{x} / \mathrm{d}$ in the range $6.65-395$.

\section{KESULTS AND DISCUSSION}

CO Emissions. Earlier measurements of soot properties using the present $5 \mathrm{~mm}$ diameter burner showed that the hydrogen coflow used to attach the flames at the burner exit affected soot concentrations $[6,8]$. Similar behavior was encountered for the $\mathrm{CO}$ measurements. Results illustrating this effect are illustrated in Fig. 1, where soot volume fractions, $f_{S}$, and mole fractions of $\mathrm{CO}, \mathrm{X}_{\mathrm{CO}}$, are plotted as a function of the ratio of hydrogen-to-fuel mass flow rates to the burner, $\dot{\mathrm{m}}_{\mathrm{H}} / \dot{\mathrm{m}}_{\mathrm{f}}$, for propylene and ethylene/air 
flames. Results for finite $\dot{\mathrm{m}}_{\mathrm{H}_{2}}$ have been linearly extrapolated to estimate properties with no hydrogen coflow while $f_{S}$ and $X_{C O}$ are normalized by these extrapolated values. Note that conditions at higher hydrogen flow rates only were used to calibrate effects of hydrogen flow.

TABLE 1. Summary of test conditions ${ }^{a}$

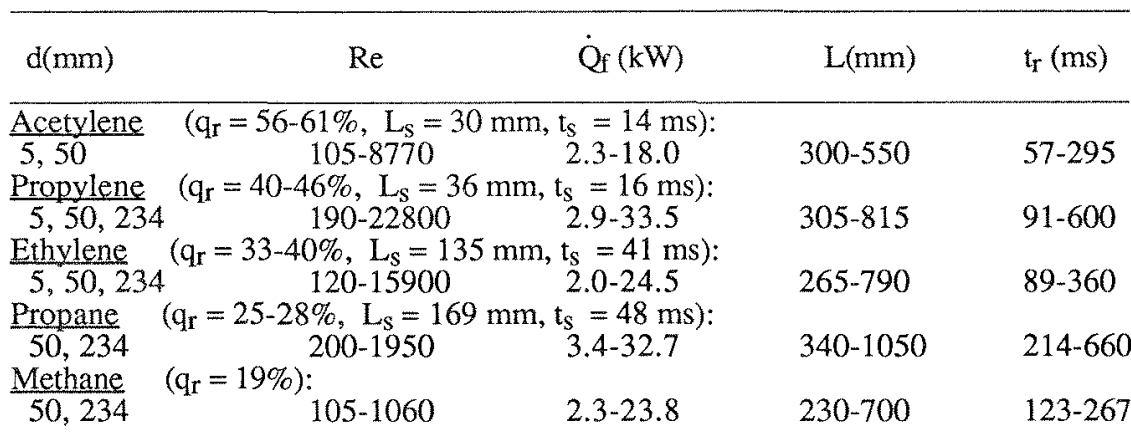

aVertical fuel injection in still air at normal temperature and pressure. Measurements along axis and at $\mathrm{r} / \mathrm{x}=0.08$. Flame length and residence times found from measurements and correlations of $[6]$.

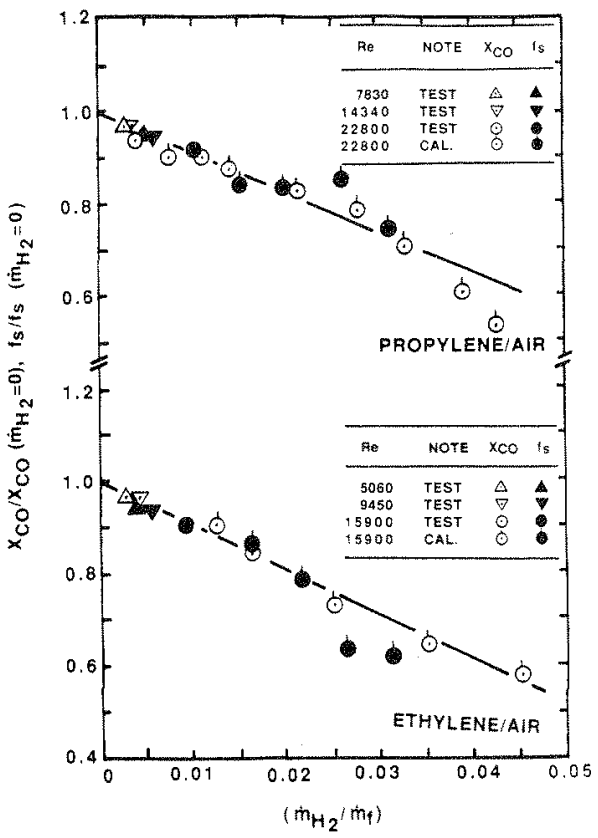

FIGURE 1. Effect of hydrogen addition on CO concentrations and soot volume fractions in the fuel-lean region of propylene and ethylene/air diffusion flames.

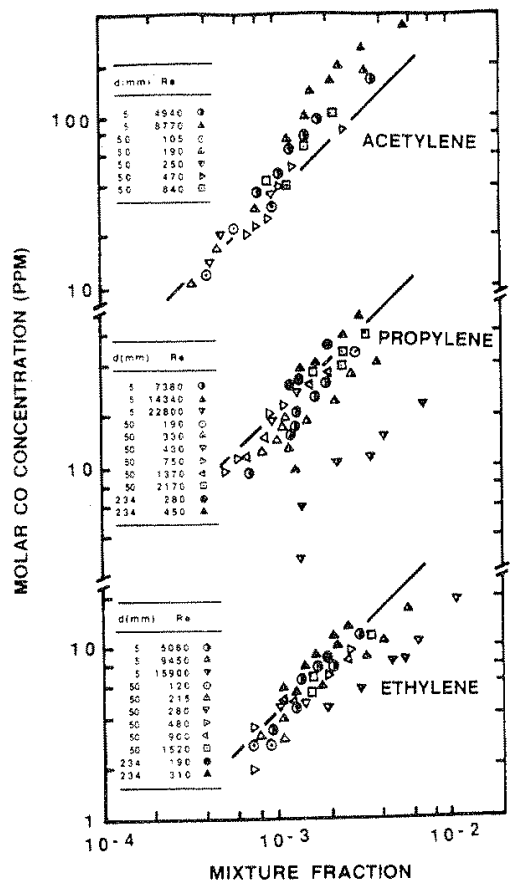

FIGURE 2. CO concentrations in the fuel-lean region of acetylene and alkene/ air diffusion flames. 
The effect of hydrogen addition on soot and $\mathrm{CO}$ emissions seen in Fig. 1 is remarkably linear with increased $\dot{\mathrm{m}}_{\mathrm{H}}$ tending to reduce emissions; therefore, linear extrapolation to $\dot{\mathrm{m}}_{\mathrm{H}_{2}}=0$ has been used in the following to estimate $\mathrm{f}_{\mathrm{S}}$ and $\mathrm{X}_{\mathrm{CO}}$ in the absence of hydrogen coflow. Another interesting feature of these results is that the effect of hydrogen addition is virtually the same for $f_{S}$ and $X_{C O}$ for each of the fuels.

Carbon monoxide concentrations (corrected for $\dot{\mathrm{m}}_{\mathrm{H}}$ for the $5 \mathrm{~mm}$ diameter burner) in the far-overfire region are plotted as a function of mixture fraction, $f$, in Fig. 2 for acetylene and the alkenes and in Fig. 3 for the alkanes. Gas temperatures are low in the region where measurements were made so that passive mixing is indicated by a linear relationship between $\mathrm{X}_{\mathrm{CO}}$ and $\mathrm{f}$, see [6] for quantitative evaluation of this approximation. Correlations of this behavior fitted to match results at long residence times, to be discussed later, are also illustrated on the figures for reference purposes.

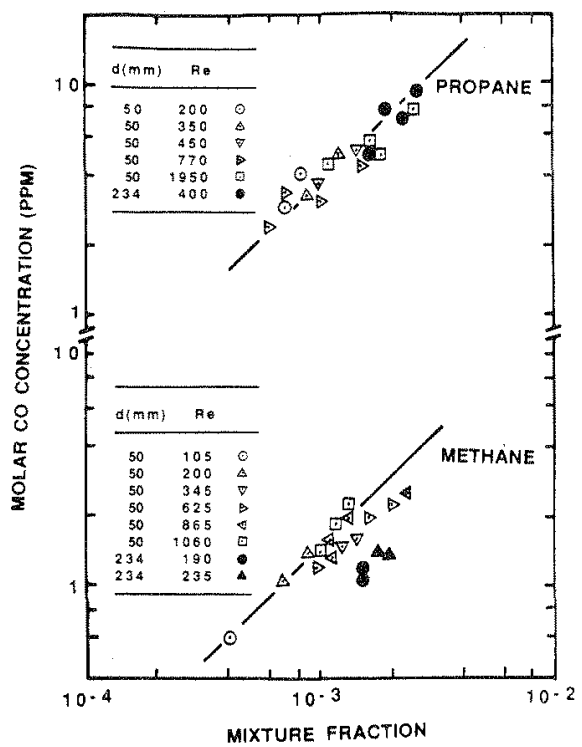

FIGURE 3. CO concentrations in the fuellean region of alkane/air diffusion flames.

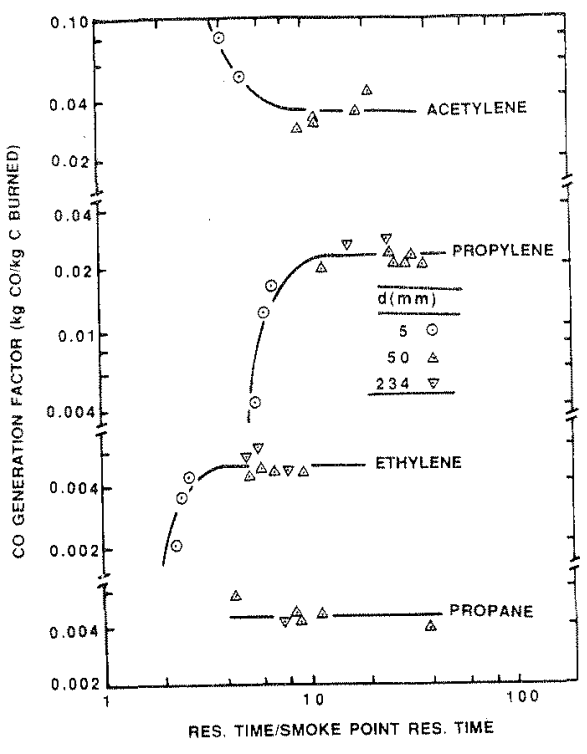

FIGURE 4. CO generation efficiencies as a function of residence time for turbulent alkane, acetylene andalkene/air diffusion flames.

Carbon monoxide concentrations plotted in Figs. 2 and 3 exhibit more scatter at a given value of $f$, as flame operating conditions change, than was observed for $f_{S}$ over the same range of test conditions [6]. However, the main trends of the results for $X_{C O}$ and $f_{S}$ are the same. First of all, results at various positions in the overfire region for any given flame satisfied a linear correlation within experimental uncertainities; as noted earlier, this indicates passive mixing of $\mathrm{CO}$ in the overfire region and that conditions when $\mathrm{CO}$ reactions quench are similar at various points along the wrinkled flame sheet. The last observation is surprising because it is expected that regions of emission near the base of the flame sheet would have shorter residence times, and thus different outcomes of finite rate CO chemistry, than regions near the tips of the turbulent flames. Next, concentrations of $\mathrm{CO}$ at particular values of $\mathrm{f}$ progressively decrease with decreasing tendency to soot - in the order acetylene, propylene, ethylene, propane and methane - implying a correspondence between the phenomena responsible for these two emissions. Additionally, concentrations of $\mathrm{CO}$ at a particular $\mathrm{f}$ 
generally increase with increasing flame residence times, eventually approaching asymptotic values at long residence times. Acetylene flames are an exception to this trend; instead, $\mathrm{CO}$ concentrations tend to decrease, even though $f_{S}$ values tend to increase [6], with increasing residence times.

The effect of flame residence time can be examined more concisely by computing $\mathrm{CO}$ generation factors, which should be constant for passive mixing and constant quenching conditions for any given flame. Analagous to the evaluation of $f, \eta_{c o}$ was found assuming that $\mathrm{H} / \mathrm{C}$ ratios were the same as the original fuel in the region where measurements were made. Then noting that $\mathrm{CO}$ and soot concentrations are small in comparison to $\mathrm{CO}_{2}$ concentrations in the far-overfire region, $\eta_{\mathrm{CO}}$ can be found from the measured $\mathrm{CO}$ and $\mathrm{CO}_{2}$ concentrations as follows:

$\eta_{\mathrm{CO}}=\mathrm{M}_{\mathrm{CO}} \mathrm{CO} /\left(\mathrm{M}_{\mathrm{C}} \mathrm{XO}_{2}\right)$

where $\mathrm{MC}_{\mathrm{C}}$ and $\mathrm{M}_{\mathrm{CO}}$ are the molecular weights of carbon and $\mathrm{CO}$. As noted earlier, $\eta_{\mathrm{CO}}$ values were relatively independent of position in a flame but varied with fuel type and flame operating condition. Thus, an average value of $\eta_{\mathrm{CO}}$ was found for each flame and associated with its residence time. The resulting values $\eta_{C O}$ are plotted as a function of residence time, normalized by the smoke point residence time, in Fig. 4 for all fuels except methane (which will be taken up later).

The results illustrated in Fig. 4 indicate that the $\eta_{C O}$ values correlate quite well with flame residence times and tend to approach asymptotic values for residence times roughly an order of magnitude longer than smoke point residence times. The behavior of $\eta_{\mathrm{CO}}$ and $\eta_{\mathrm{s}}$ for propylene and ethylene/air flames is qualitatively similar: both tend to increase at small residence times and then approach their asymptotic values. Earlier measurements showed a progressive increase of $\eta_{\mathrm{s}}$ with residence time for propane [6] but retesting yielded asymptotic behavior (nearly constant $\eta_{\mathrm{S}}$ over the test range) instead; thus, nearly constant values of $\eta_{C O}$ for propane over the test range is consistent with the findings for propylene and ethylene. However, the behavior of $\eta_{C O}$ and $\eta_{s}$ for acetylene differs from the rest with $\eta_{C O}$ decreasing and $\eta_{\mathrm{s}}$ increasing as their asymptotic values are approached.

Results corresponding to Fig. 4 cannot be plotted for methane because its laminar smoke point residence time is unknown. Additionally, the present turbulent methane flames did not emit any soot, based on extensive observations using the optical/sampling probe of [6] and as well as thermophoretic sampling and observations using TEM. Thus, the $\eta_{C O}$ for methane are summarized in Table 2 , ordering the values with increased residence times. The results scatter due to large experimental uncertainities, because the $\mathrm{X}_{\mathrm{CO}}$ are small for methane, but the trends are similar to propane with $\eta_{\mathrm{CO}}$ being relatively independent of residence time for the present test range. Additionally, $\eta_{C O}$ for methane is much smaller than the rest, cf. Fig. 4, suggesting small emissions of $\mathrm{CO}$ that are not associated with soot which may still contribute to $\mathrm{CO}$ emissions from sooting flames.

Correlation of $\mathrm{CO}$ and Soot Emissions. Past observations of a relationship between $\mathrm{CO}$ and soot emissions from sooting buoyant turbulent diffusion flames [1], the present observation that both exhibit asymptotic behavior at long resident times, and the low-levels of $\mathrm{CO}$ emissions from nonsooting methane flames, prompted an examination of the relationship between the two emissions. This was done based on the earlier soot generation factor measurements of [6] except for correction of the propane results mentioned earlier. These results involve laser extinction measurements at $632.8 \mathrm{~nm}$, assuming the small particle (Rayleigh) scattering limit, which were reduced to soot volume fractions using the refractive indices of Dalzell and Sarofim [15] similar to past work [8]. Finally, the soot volume 
fractions were converted to soot generation efficiencies using a soot density of $1100 \mathrm{~kg} / \mathrm{m}^{3}$ from Newman and Steciak [16].

TABLE 2. Summary of $\eta_{C O}$ for methane/air flames ${ }^{a}$

\begin{tabular}{lrllrlll}
\hline $\begin{array}{c}\mathrm{d} \\
(\mathrm{mm})\end{array}$ & $\mathrm{Re}$ & $\begin{array}{l}\mathrm{tr}_{\mathrm{r}} \\
(\mathrm{ms})\end{array}$ & $\eta_{\mathrm{CO}}$ & $\begin{array}{c}\mathrm{d} \\
(\mathrm{mm})\end{array}$ & $\mathrm{Re}$ & $\begin{array}{l}\mathrm{t}_{\mathrm{r}} \\
(\mathrm{ms})\end{array}$ & $\eta_{C O}$ \\
\hline 50 & 1060 & 267 & 0.0022 & 234 & 235 & 162 & 0.0009 \\
50 & 865 & 249 & 0.0018 & 50 & 200 & 153 & 0.0021 \\
50 & 625 & 224 & 0.0016 & 234 & 190 & 150 & 0.0010 \\
50 & 345 & 184 & 0.0016 & 50 & 105 & 123 & 0.0020 \\
\hline
\end{tabular}

aResidence times found from correlation of [6].

The correlation between CO and soot generation factors is illustrated in Fig. 5. Similar to Fig. 4 , data only are identified by the fuel and burner size to avoid cluttering the figure. In addition to the present results, correlations also have been computed from the extensive tabulation of Tewarson [2], drawn from a variety of sources (these $\eta_{\mathrm{S}}$ values were based on extinction measurements using a soot density of $1100 \mathrm{~kg} / \mathrm{m}^{3}$, similar to the present values). Present results involve all residence times, not just the asympotic regime, however, limiting the data to the asymptotic range yields essentially the same results because measurements for asymptotic conditions dominate the database. Flame conditions are not specified in [2] but presumably involve large flames in the long residence time regime; they also involve averages over the entire plume above the fires. Finally, the $\mathrm{CO}$ generation factors for the nonsooting methane flames are shown at the left of the plot, to suggest a baseline for a soot generation factor of zero.

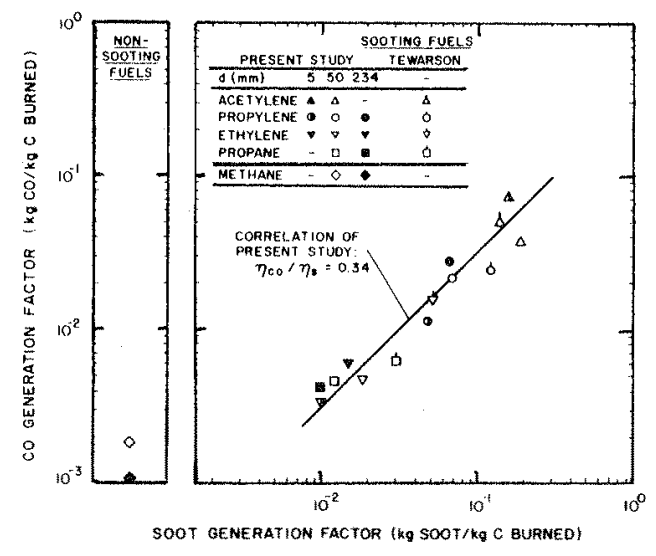

FIGURE 5. Correlation between $\mathrm{CO}$ and soot generation efficiencies for turbulent alkane, acetylene and alkene/air diffusion flames.

The results illustrated in Fig. 5 exhibit a strong correlation between $\eta$ co and $\eta_{s}$. The correlation of present measurements can be quantified reasonably well by a linear fit:

$\eta_{\mathrm{CO}}=0.34 \eta_{\mathrm{s}}$ 
which is also illustrated in the figure. The standard deviation of the fit over the test range is 0.09 . The results from Tewarson [2] are seen to be in reasonably good agreement with this fit as well. The correlation clearly suggests a relationship between mechanisms responsible for soot and CO emissions in flames, associated with processes in the soot layer as it passes through the flame sheet. The details of the process should be studied but similarities between $\mathrm{CO}$ and soot oxidation [1], and the tendency of flames having larger soot concentrations to have lower maximum temperatures due to increased radiative heat losses (see $\mathrm{qr}$ in Table 1 and Refs. 1-6,8,12 and13) are undoubtedly important factors in the behavior. Additionally, the fact that the correlation is relatively independent of the $\mathrm{H} / \mathrm{C}$ ratio of the fuels is consistent with the similar reductions of $\mathrm{X}_{\mathrm{CO}}$ and $\mathrm{f}_{\mathrm{S}}$ with increasing hydrogen coflow seen in Fig. 1. Finally, use of Eq.(2) for $\eta_{s}$ less than 0.01 is questionable because results for the nonsooting methane flames suggest that $\mathrm{CO}$ emissions not associated with soot emissions could become appreciable at these conditions.

Findings concerning $\mathrm{CO}$ and soot emissions in the long residence time regime are summarized in Table 3 for all the fuels. Entries include $\eta_{\mathrm{CO}}, \eta_{\mathrm{s}}$ and their ratio $\eta_{\mathrm{CO}} / \mathrm{s}$ $=\eta_{\mathrm{CO}} / \eta_{\mathrm{s}}$, which represents the mass of $\mathrm{CO}$ per unit mass of soot emitted from the flames. The table also includes values of these parameters from Tewarson [2] and values of $\eta_{s}$ from Newman and Steciak [16]. All $\eta_{S}$ values were based on extinction measurements using a soot density of $1100 \mathrm{~kg} / \mathrm{m}^{3}$. Like [2], flame conditions are not specified in [16] but presumably involve large flames in the long residence time regime with averages obtained over the entire plume above the fires.

TABLE 3. Summary of $\mathrm{CO}$ and soot generation factors ${ }^{\mathrm{a}}$

\begin{tabular}{|c|c|c|c|c|c|}
\hline Fuel & Acetylene & Propylene & Ethylene & Propane & Methane \\
\hline \multicolumn{6}{|l|}{ пCO: } \\
\hline Present & 0.036 & 0.022 & 0.0048 & 0.0044 & 0.0018 \\
\hline Tewarson [2] & 0.049 & 0.023 & 0.015 & 0.0060 & --.---- \\
\hline \multicolumn{6}{|l|}{$\eta_{\mathrm{s}}:$} \\
\hline Present & 0.19 & 0.067 & 0.018 & 0.012 & 0.00 \\
\hline Tewarson [2] & 0.14 & 0.12 & 0.053 & 0.031 & $-\ldots$ \\
\hline $\begin{array}{l}\text { Newman and } \\
\text { Steciak [16] }\end{array}$ & $\cdots$ & 0.063 & 0.017 & 0.021 & \\
\hline \multicolumn{6}{|l|}{$\eta_{\mathrm{CO}} / \mathrm{s}$} \\
\hline Tewarson [2] & 0.35 & 0.19 & 0.28 & 0.20 & \\
\hline
\end{tabular}

aPresent results for the long residence time regime. All $\eta_{\mathrm{s}}$ estimated from optical measurements using a soot density of $1100 \mathrm{~kg} / \mathrm{m}^{3}$.

Present values of $\eta_{\mathrm{CO}}$ and those of [2], generally are in fair agreement. The main exception is $\eta_{\mathrm{CO}}$ for ethylene where the value from [2] is roughly three times larger than the present value. There are larger discrepancies between present measurements and those of [2] for $\eta_{\mathrm{S}}$, however, present results are in good agreement with the recent findings of Newman and Steciak [16], except for propane where present values are low. Tewarson's [2] value of $\eta_{\mathrm{s}}$ for ethylene is also about three times higher than the rest similar to the ratio for $\eta_{\mathrm{CO}}$; this suggests possible underestimation of the mixture fraction for both these determinations. Finally, the values of $\eta_{\mathrm{CO} / \mathrm{s}}$ from [2] and the present study also are similar. While some fuelto-fuel variability of $\eta_{\mathrm{CO}} / \mathrm{s}$ is to be expected, the values listed in Table 3 vary in a narrow 
range in spite of large variations of sooting tendencies, $\mathrm{H} / \mathrm{C}$ ratios varying in the range 1-2.67, and a large range of maximum flame temperatures. This tends to support similarities of the oxidation of $\mathrm{CO}$ and soot as a major factor in the correlation between these emissions. Additionally, a synergism of hazards of $\mathrm{CO}$ and soot for gaseous hydrocarbon/air flames appears to be established. Finally, the close relationship between $\mathrm{CO}$ and soot emissions, which apparently involves material within the soot layer being drawn through the flame sheet, provides one explanation for the limited success of past attempts to predict $\mathrm{CO}$ emissions from turbulent diffusion flames which ignore the presence of soot [17].

\section{CONCLUSIONS}

1. Similar to soot generation factors [6], CO generation factors were uniform throughout the overfire region for a given fuel and operating condition, implying both passive mixing in the overfire region and constant soot concentrations, CO concentrations, and mixture fractions when reactions quench -- independent of position within the flame.

2. Similar to soot generation factors [6], CO generation factors of sooting fuels were largely functions of the flame residence time, increasing or decreasing with increasing residence times depending on the fuel but approaching asymptotic constant values at residence times roughly an order of magnitude longer than the normal smoke point residence time.

3. There is a strong correlation between $\mathrm{CO}$ and soot emissions yielding a synergism of the fire hazards associated with each of these emissions as well as potential similarities between the mechanisms responsible for their emissions. A reasonable fit of the correlation between the generation factors is $\eta_{C O}=0.34 \eta_{\mathrm{S}}$ over the present test range (with a standard deviation of 0.09 ).

4. Nevertheless, there is a component of CO emissions that is not associated with soot, based on observations of low level CO emissions from methane/air flames - all of which were nonsooting for present test conditions.

\section{ACKNOWLEDGMENTS}

The authors wish to acknowledge helpful discussions with R. Friedman, Factory Mutual Research, W. M. Pitts, of NIST, and R. J. Santoro, of The Pennsylvania State University. The research was sponsored by the Center for Fire Research of NIST, Grant No 60NANB8DO833, with H. R. Baum serving as Scientific Officer.

\section{REFERENCES}

1. Friedman, R., "Some Unresolved Fire Chemistry Problems," Fire Safety Science: Proceedings of the First International Symposium, pp. 349-359, Hemisphere, Washington, D.C., 1986.

2. Tewarson, A., "Generation of Heat and Chemical Compounds in Fires," in SFPE Handbook of Fire Protection Engineering, pp. 1-179 to 1-199, NFPA, Quincy, MA, 1988 .

3. Tewarson, A. and Newman, J.S., "Scale Effects on the Fire Properties of Materials," Fire Safety Science: Proceedings of the First International Symposium, pp. 451-462, Hemisphere, Washington, D.C., 1986.

4. Fischer, S.J. and Grosshandler, W.L., "Radiance, Soot and Temperature Interactions in Turbulent Alcohol Fires," Twenty-Second Symposium (International) on Combustion, pp. 1241-1249, The Combustion Institute, Pittsburgh, 1988. 
5. McCaffrey, B.J. and Harkleroad, M., "Combustion Efficiency, Radiation, CO and Soot Yield from a Variety of Gaseous, Liquid and Solid Fueled Buoyant Diffusion Flames," Twenty-Second Symposium (International) on Combustion, pp. 1251-1261, The Combustion Institute, Pittsburgh, 1988.

6. Sivathanu, Y.R. and Faeth, G.M., "Soot Volume Fractions in the Overfire Region of Turbulent Diffusion Flames," Combust. Flame, 81:133-149, 1990.

7. Bilger, R.W., "Reaction Rates in Diffusion Flames," Combust. Flame, 30:277-284, 1977.

8. Gore, J.P. and Faeth, G.M, "Structure and Radiation Properties of Luminous Turbulent Acetylene/Air Diffusion Flames," J. Heat Trans., 110:173-181, 1988.

9. Sivathanu, Y.R. and Faeth, G.M., "Generalized State Relationships for Scalar Properties in Nonpremixed Hydrocarbon/Air Flames," Combust. Flame, 82:211-230, 1990.

10. Dixon-Lewis, G., David, T., Gaskell, P.H., Fukutani, S., Jinno, H., Miller, J.A., Kee, R.J., Smooke, M.D., Peters, N., Effelsberg, E., Warnatz, J. and Behrendt, F., "Calculation of the Structure and Extinction Limit of a Methane-Air Counterflow Diffusion Flame in the Forward Stagnation Region of a Porous Cylinder," Twentieth Symposium (International) on Combustion, pp. 1893-1904, The Combustion Institute, Pittsburgh, 1984.

11. Gore, J.P., Jeng, S.-M. and Faeth, G.M., "Spectral and Total Radiation Properties of Turbulent Carbon Monoxide/Air Diffusion Flames," AIAA J., 25:339-345, 1987.

12. Sivathanu, Y.R. and Faeth, G.M, "Temperature/Soot Volume Fraction Correlations in the Fuel Rich Region of Buoyant Turbulent Diffusion Flames," Combust. Flame, 81:150-165, 1990.

13. Markstein, G.H., "Relationship Between Smoke Point and Radiant Emission from Buoyant Turbulent and Laminar Diffusion Flames," Twentieth Symposium (International) on Combustion, pp. 1055-1061, The Combustion Institute, Pittsburgh, 1984.

14. Schug, K.P., Manheimer-Timnat, Y., Yaccarino, P. and Glassman, I., "Sooting Behavior of Gaseous Hydrocarbon Diffusion Flames and the Influence of Additives," Combust. Sci. Tech., 22:235-250, 1980.

15. Dalzell, W.H. and Sarofim, A.F., "Optical Constants of Soot and Their Application to Heat-Flux Calculations," J. Heat Trans., 21:100-104, 1969.

16. Newman, J.S. and Steciak, J., "Characterization of Particulates from Diffusion Flames," Combust. Flame, 67:55-64, 1987.

17. Bilger, R.W. and Stårner, S.H., "A Simple Model for Carbon Monoxide in Laminar and Turbulent Hydrocarbon Diffusion Flames," Combust. Flame, 51: 155-176, 1983. 